\title{
The Vorticity Budgets of North Atlantic Winter Extratropical Cyclone Life Cycles in MERRA Reanalysis. Part II: Decaying Phase*
}

\author{
ROOHOLLAH AZAD \\ Geophysical Institute, University of Bergen, Bergen, Norway \\ ASGEIR SORTEBERG \\ Geophysical Institute, and Bjerknes Centre for Climate Research, University of Bergen, Bergen, Norway
}

(Manuscript received 30 August 2013, in final form 21 May 2013)

\begin{abstract}
The role of physical forcing mechanisms that contribute to the decay of winter North Atlantic extratropical cyclones during the period 1979-2009 are examined using the Modern-Era Retrospective Analysis for Research and Applications (MERRA). The paired Zwack-Okossi tendency equation and omega equation explained in part I of this paper is employed to investigate the total effects of forcing processes (the direct effect of the forcing mechanisms and the indirect effect of the induced adiabatic cooling) that dissipate the 950-hPa cyclonic geostrophic vorticity at the cyclone center.

Composite analyses reveal that the commencement of the decay is associated mainly with the upper-level anticyclonic vorticity advection, cold-air advection, and positive ageostrophic vorticity tendency. The secondary contributor to the dissipation of cyclonic circulation is the lower-tropospheric adiabatic cooling induced mainly by friction and positive ageostrophic vorticity tendency. The dynamics is found to be different at the beginning of the decay than in the later stages. While the negative tilt of troughs aloft and the surface cyclone is required for cyclolysis to occur, low air processes show a greater effect in the termination of the low pressure systems. Further, the total effect of the vorticity advection and temperature advection terms are modest, while the ageostrophic vorticity tendency and friction terms show a greater total negative contribution. This is because the two latter terms decrease the cyclonic geostrophic vorticity at the low center through both their direct and indirect effects. The latent heat release maximizing at $800-700 \mathrm{hPa}$ produces cyclonic circulation, thus reducing the spindown of decaying cyclones.
\end{abstract}

\section{Introduction}

Among the different stages of the cyclone life cycle, the decaying stage has received less attention, probably because it is associated with smaller amounts of precipitation, weaker vertical circulation, and weaker nearsurface wind speeds. Our understanding of the physical processes during the dissipation period of the cyclone life cycle is therefore much less than that for the

\footnotetext{
* Supplemental information related to this paper is available at the Journals Online website: http://dx.doi.org/10.1175/JAS-D-130266.s1.

Corresponding author address: Roohollah Azad, Geophysical Institute, University of Bergen, Allegaten 70, 5007 Bergen, Norway.

E-mail: roohollah.azad@gfi.uib.no
}

incipient and evolving stages. The paucity of studies on cyclone decay may have left weather and climate prediction models with inadequate physics, such as friction parameterization (e.g., Doyle 1995).

The mature stage of the life cycle of synoptic-scale cyclones in midlatitudes often exhibits a complicated occluded structure. As the occlusion forms, cyclone development slows down and the low-level horizontal temperature gradients in the cyclone area decrease, resulting in weaker temperature advections and smaller low-level convergences. The process of occlusion is not due to frontal movement but rather can be viewed as a rearrangement of mass brought about by quasigeostrophic forcing (Carlson 1994). Although dissipation may occur after the occlusion starts (Schultz and Vaughan 2011), it is the structural and dynamical transformations in the occluded air that are responsible for the deterioration of the cyclonic 
circulation. The conceptual Bergen school model of extratropical cyclone (ETC) development (Bjerknes and Solberg 1922) and the Shapiro-Keyser marine ETC life-cycle model (Shapiro and Keyser 1990) do not include adequate explanations for the occluded and dissipating phases.

The decay stage of extratropical low pressure systems is associated with rising sea level pressure (SLP), and therefore the reduction of near-surface cyclonic geostrophic vorticity (CGV) at the cyclone center. The processes that reduce $\mathrm{CGV}$ at the surface weaken the upward vertical motion over the cyclone and, as a result, suppress low-level convergence and induced cyclonic circulation. Upper-tropospheric fields play an important role in the decay of ETCs. The low pressure weakens only once the westward tilt with height between the upper-level trough and the surface cyclone starts to decrease, in some cases changing sign (e.g., Bengtsson et al. 2009). This eastward shift in the position of the upper-level divergence relative to surface hinders the evacuation of mass near the cyclone center, thus initiating the decaying period (e.g., Martin et al. 2001).

Climatologies of dynamics of ETC decay are in very short supply. This work is inspired by the recognition that the climatologies of upper- and lower-level mechanisms, as dynamically and thermally necessary ingredients for the decay of surface low pressure systems, can be explored by the Zwack-Okossi equation (Zwack and Okossi 1986). This tendency equation includes the physical forcing processes at all pressure levels in the troposphere and lower stratosphere and thus can be used to isolate the forcing contributions from each level. We focus on the structure of cyclolysis dynamics and the degree of case-to-case variability that exists. The latter is accomplished by defining constant-population subcomposites similar to those explained in Azad and Sorteberg (2014, hereafter Part I), except that DAY2, DAY3, and DAY4 subsets contain those events that terminate at least 2,3 , and 4 or more days, respectively, beyond the peak intensity (the time of the maximum 950-hPa geostrophic vorticity at the cyclone center for each event). There are 38, 36, and 24 cyclones in the DAY2, DAY3, and DAY4 subsets, respectively. There are also 2 out of 100 cyclones that terminate at least 1 day after the peak intensity, and they are classified in the DAY2 subset. The data, diagnostic equations, composite methodology, numerical procedures, and parameterizations are all introduced and explained in Part I. The second part presented here includes the composite results at the surface cyclone center for the period of decay. Section 2 summarizes the previous findings concerning the dissipation of the ETCs in the
Zwack-Okossi (Z-O) equation. Sections 3 and 4 present our composite results, and section 5 contains our concluding remarks.

\section{Cyclone decay in the $\mathrm{Z}-\mathrm{O}$ equation}

The Z-O tendency equation has been used in previous studies to diagnose the contribution of dynamic and thermodynamic processes to the development and decay of ETCs over the North Atlantic (Lupo et al. 1992; Rolfson and Smith 1996; Walthorn and Smith 1998; Morris and Smith 2001; Parsons and Smith 2004). The main objective in these studies was to examine the contribution of synoptic-scale forcing mechanisms (i.e., vorticity advection, temperature advection, latent heat release, and adiabatic cooling) to the near-surface geostrophic vorticity $(\mathrm{GV})$ tendency. A review of prior studies that used the $\mathrm{Z}-\mathrm{O}$ equation to diagnose the end of the cyclone life cycle is presented here in order to establish a basis for comparison for our composite results.

Lupo et al. (1992) employed a modified form of the $\mathrm{Z}-\mathrm{O}$ equation to investigate the development of a land explosive cyclone and a marine explosive cyclone. Their results indicate that, for the marine case, the negative GV tendency at the end of the explosive period is mainly forced by the adiabatic cooling term. The decay of the land case is associated with negative contributions by the temperature advection term. In addition, for both cases, the counteractive effect of frictional forcing is largest at the end of the development, while sensible heating induces fairly small negative $950-\mathrm{hPa}$ GV tendency at the marine cyclone center.

In the study of Rolfson and Smith (1996), a weakening category is included in the composite analysis of 12 wintertime, land extratropical cyclones over the United States and southern Canada. They find that the decay in the weakening cyclones is forced by the temperature advection, as the cold-air advection in the lower and middle troposphere $(900-500 \mathrm{hPa}$ ) dominates the upperlevel (above $400 \mathrm{hPa}$ ) warm-air advection. Further, the positive contribution of the vorticity advection term is smaller, mainly because of the prominent anticyclonic vorticity advection in the lower-tropospheric levels that offsets the weak cyclonic vorticity advection in the upper troposphere and lower stratosphere. The adiabatic cooling term, which acts to oppose the cyclone deepening, makes a small positive contribution at the cyclone center as a result of downward vertical motion occurring in $700-500 \mathrm{hPa}$. Finally, the small precipitation rate in the weakening category, along with the positioning of the cyclone center in the boundary of the latent heating 
(a)

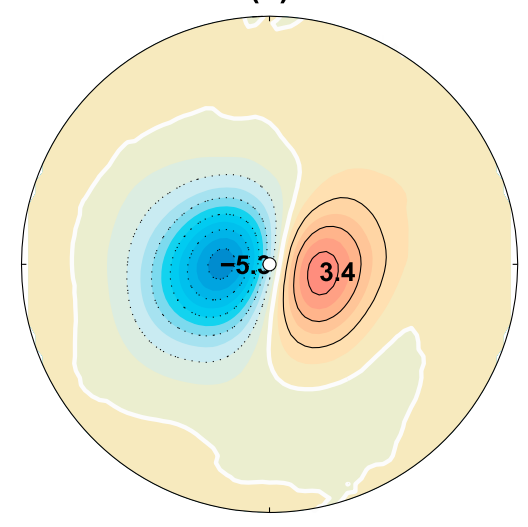

(d)

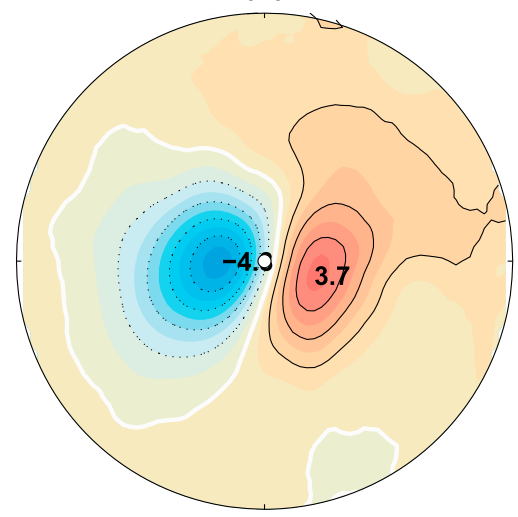

(b)

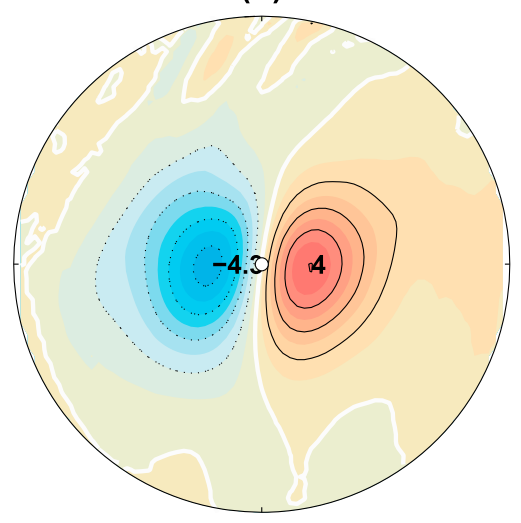

(e)

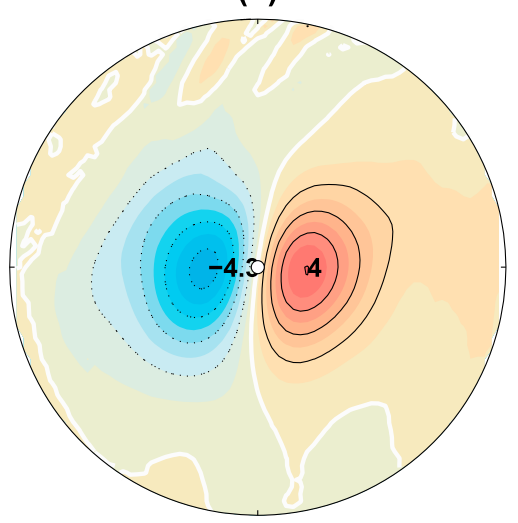

(c)

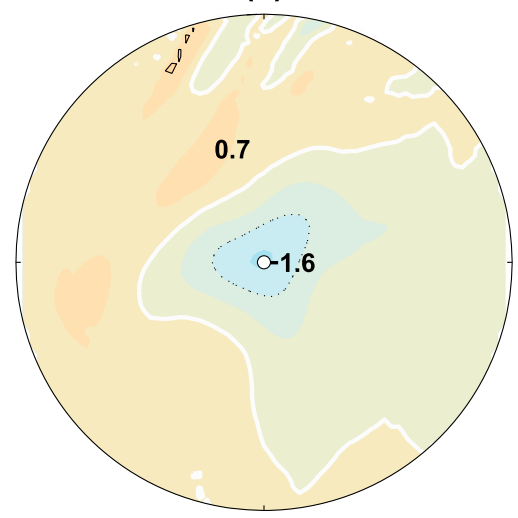

(f)

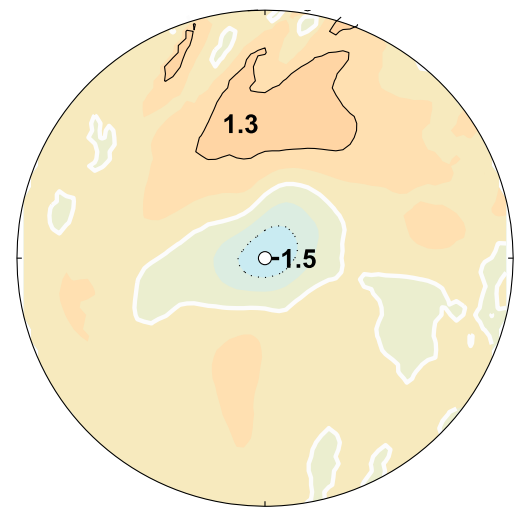

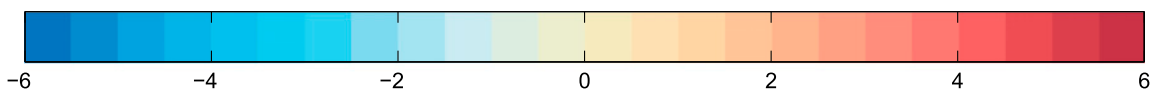

FIG. 1. Composites of (a)-(c) the reanalysis and (d)-(f) Z-O 950-hPa GV tendency $\left(10^{-9} \mathrm{~s}^{-2}\right)$ averaged for the entire development phase. Fields are the (a),(d) 950-hPa GV tendencies; (b),(e) its system advection; and (c),(f) the development parts on a $10^{\circ}$-radius region for the decaying phase. The white circle and lines show the cyclone center and the zero tendencies, respectively. The direction of the movement of the composite cyclone is to the right.

region, leads to a negative contribution by the latent heat release term.

The observational studies mentioned above demonstrate that the $\mathrm{Z}-\mathrm{O}$ equation yields useful information about the dynamics of ETC development and decay. Walthorn and Smith (1998) performed a case study using the National Center for Atmospheric Research's (NCAR) Community Climate Model version 2 (CCM2) general circulation model to examine whether cyclones that are not initialized with observational data develop or decay realistically. Their diagnosis, which includes a period of explosive development and a period of decay, indicates that the end of the simulated cyclone development is associated with a simultaneous reduction in vorticity advection, temperature advection, and latent heating contributions in the $\mathrm{Z}-\mathrm{O}$ equation. In accordance with the observational diagnoses, the decay of the simulated cyclone is accompanied by a reduction in the vorticity advection contribution and a sign reversal of the temperature advection influence. Thus, the processes that were responsible for the pressure fall at the simulated cyclone center could not overcome the negative effects of the adiabatic cooling, sensible heating, and friction terms.

To further document the decaying phase of the ETC life cycle, Morris and Smith (2001) examined two decaying cyclone cases that occurred over the continental United States using the modified form of the $\mathrm{Z}-\mathrm{O}$ equation, which includes only the synoptic-scale forcing terms. Their results show that, even though the contribution of each term varied during the period of weakening, 

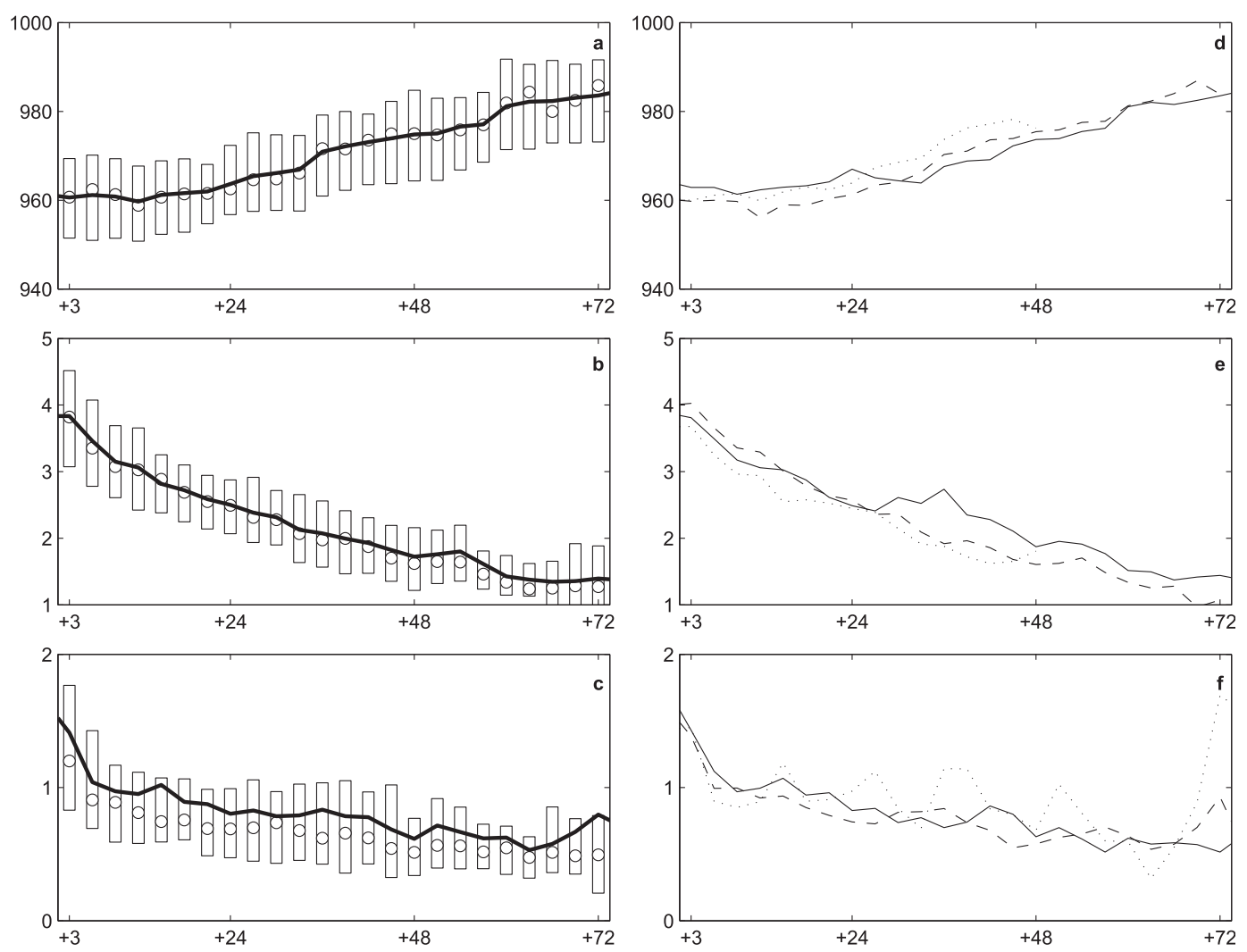

FIG. 2. (left) Evolution of the composite (a) sea level pressure (hPa), (b) 950-hPa geostrophic vorticity $\left(10^{-4} \mathrm{~s}^{-1}\right)$, and (c) precipitation rate $\left(10^{-4} \mathrm{~kg} \mathrm{~m}^{-2} \mathrm{~s}^{-1}\right)$ at the cyclone center for the period of 3 days $(72 \mathrm{~h})$ after peak intensity (see text). Boxes are the 25th-75th percentiles, circles are the median, and the solid thick line is the mean. (right) The life cycle of subcomposite (d) sea level pressure, (e) 950-hPa GV, and (f) precipitation rate for cyclones that terminate at least 2 (dotted), 3 (dashed), and 4 or more days (solid) after the peak intensity.

the decay onset was associated with cold-air advection at middle and lower levels over the cyclone center in both cases. Meanwhile, the westward tilt with height in both cases results in a positive contribution by the vorticity advection term at the beginning of the decay period. The superposition of the upper-level trough over the surface cyclone center occurs after the decay onset. While the latent heating and adiabatic cooling terms are generally small, the adiabatic cooling term is positive as a result of downward vertical motions.

In the present study, following the methodology explained in Part I, we examine the direct, indirect, and total composite contributions of forcing terms in the full $\mathrm{Z}-\mathrm{O}$ equation [Eq. (1) in Part I] to the $950-\mathrm{hPa} \mathrm{GV}$ tendency during the decaying phase. The direct effect is the effect of the dynamical and thermodynamical forcing mechanisms, while the indirect effect is the effect of the adiabatic cooling term. The total effect is the sum of the direct and indirect effects. To provide further insight into the dynamics of marine cyclone systems in the decaying stage, we investigate the processes that limit the CGV increases and the SLP falls. The composite results presented in the next section are divided into two parts. The first part shows the life cycle of the reanalysis and Z-O geostrophic vorticity tendencies, as well as the contributions by the vertically integrated $\mathrm{Z}-\mathrm{O}$ forcing processes at the cyclone center. In the second part, we provide time cross sections over the cyclone center to illustrate how forcing processes at different pressure levels change CGV at the surface. Finally, it should be mentioned that in contrast to individual cyclone analyses, the composites in this study allow us to assess the degree of case-to-case variability in contributions by forcing mechanisms, thus revealing both the weak and strong case-dependent features of cyclolysis.

\section{Reanalysis and Z-O tendency comparisons}

Recall that the decaying phase is the period after the time $t_{c}$ at which the $950-\mathrm{hPa} \mathrm{GV}$ reaches its maximum at the cyclone center. The reanalysis tendencies are the 

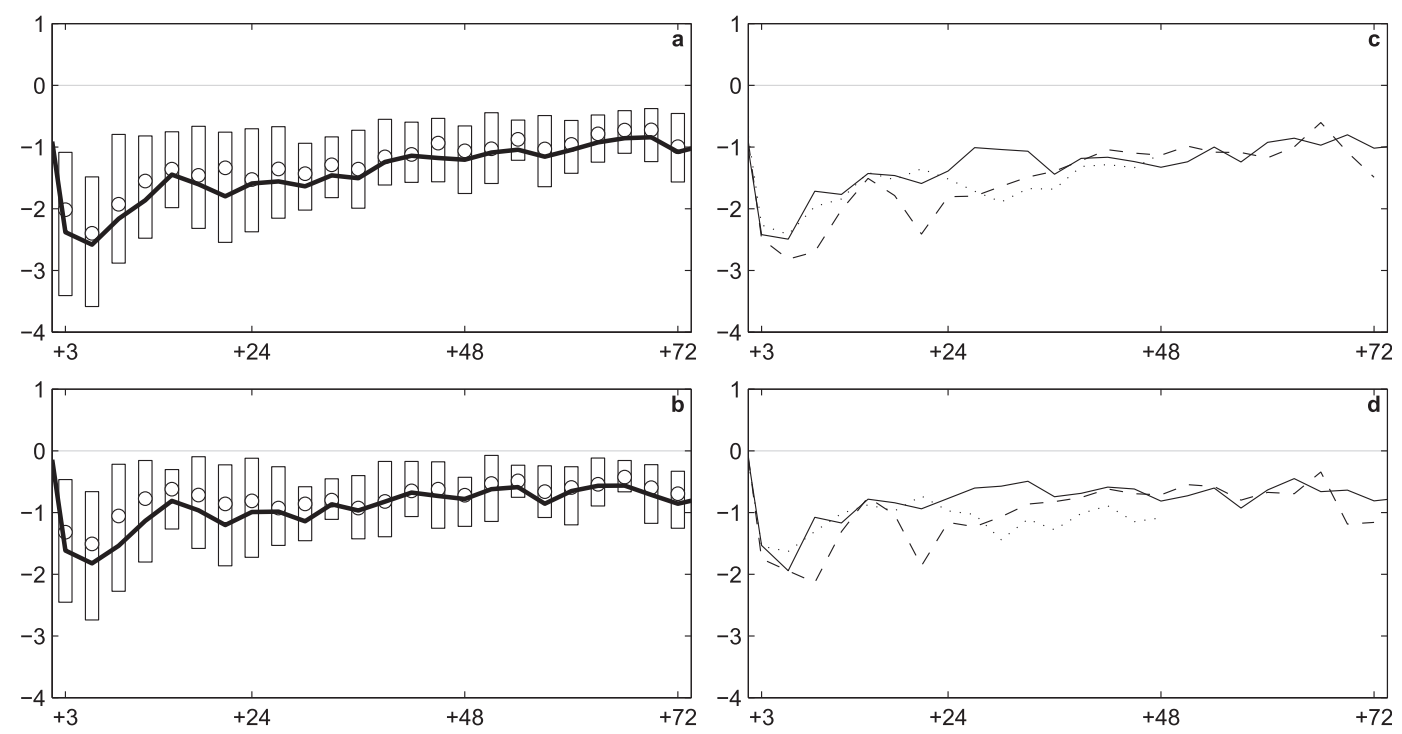

FIG. 3. As in Fig. 2, but for the composite 950-hPa (a),(c) Z-O and (b),(d) reanalysis GV tendencies $\left(10^{-9} \mathrm{~s}^{-2}\right)$.

12-h central finite differences of GV at $950 \mathrm{hPa}$ [see Part I, Eq. (7)], while $\mathrm{Z}-\mathrm{O}$ tendencies are vertically integrated forcing processes [see Part I, Eq. (1)] at the same level. To reduce the errors in determining the
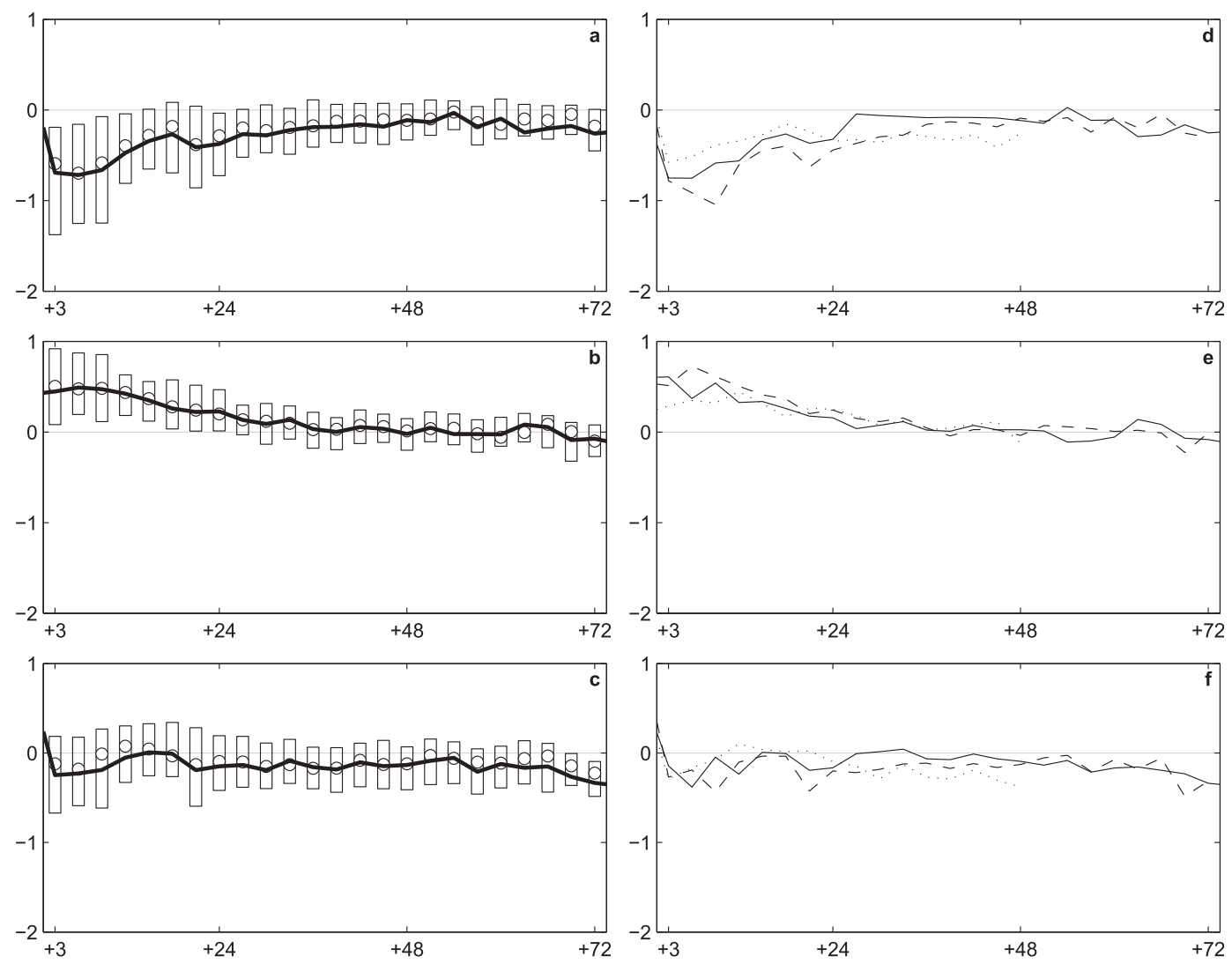

FIG. 4. As in Fig. 2, but for the (a),(d) direct; (b),(e) indirect; and (c),(f) total effect of the vorticity advection term on the 950-hPa GV tendencies $\left(10^{-9} \mathrm{~s}^{-2}\right)$. 

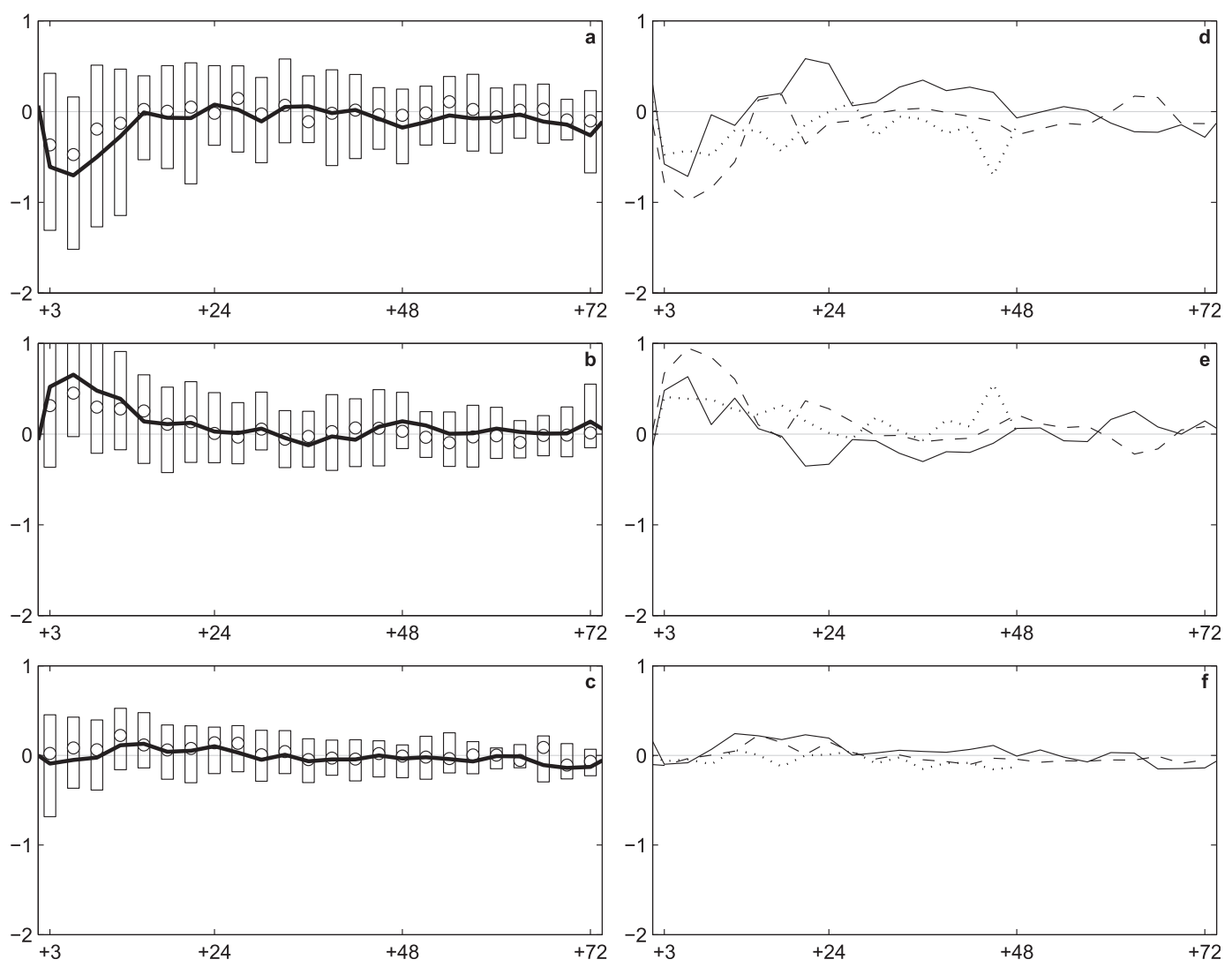

FIG. 5. As in Fig. 2, but for the (a),(d) direct; (b),(e) indirect; and (c),(f) total effect of the temperature advection term on the $950-\mathrm{hPa} \mathrm{GV}$ tendencies $\left(10^{-9} \mathrm{~s}^{-2}\right)$.

reintensification periods by considering only the negative $\mathrm{Z}-\mathrm{O}$ tendencies.

\section{a. Reanalysis and $\mathrm{Z}-O$ tendencies in the cyclone area}

The composite reanalysis and Z-O geostrophic vorticity tendencies at $950 \mathrm{hPa}$ for the entire period of decay are shown in Fig. 1 on a $10^{\circ}$-geodesic-radius region $(\sim 1100 \mathrm{~km})$. All tendency fields were rotated to the direction of cyclone movement before averaging to make composites (for details, see Part I). The distribution of positive-negative tendency couplets suggests that the size of the composite cyclone is smaller than the $10^{\circ}$ radius. We can see that the system advection tendency accounts for a significant portion $(\sim 70 \%)$ of the $\mathrm{GV}$ tendencies in the cyclone area and that it is zero at the cyclone center. The horizontal pattern of the reanalysis tendency correlates well with the $\mathrm{Z}-\mathrm{O}$ tendency $(89 \%)$, but the $\mathrm{Z}-\mathrm{O}$ tendency is slightly weaker than the reanalysis value. One source of the differences is possibly the numerical truncation errors in the calculation of the forcing terms. Parameterizations of latent heat release and friction could also result in some errors (see Part I). Also, the $\mathrm{Z}-\mathrm{O}$ tendency is an instantaneous value while the reanalysis is the 12 -h finite difference.

\section{b. Evolution of 950-hPa GV, SLP, and precipitation rate}

Figure 2 shows the time evolution of the composite 950-hPa GV, SLP, and precipitation rate at the cyclone center for the period from $3 \mathrm{~h}(+3 \mathrm{~h})$ to 3 days $(+72 \mathrm{~h})$ beyond $t_{c}$. The evolution of $950-\mathrm{hPa} \mathrm{GV}$ resembles the SLP evolution, confirming the former as a suitable variable for analyzing surface cyclone dynamics. The lengths of quantile boxes are approximately $15 \mathrm{hPa}$, $1 \times 10^{-4} \mathrm{~s}^{-1}$, and $0.5 \times 10^{-4} \mathrm{~kg} \mathrm{~m}^{-2} \mathrm{~s}^{-1}$ for SLP, GV, and precipitation rate composites, respectively. Note also that the minimum SLP occurs in a period of 3-12 h after $t_{c}$ (Fig. 2d). This leads to a gentle change in the composite SLP curve in the first $12 \mathrm{~h}$ of the decay (Fig. 2a). However, the 950-hPa GV decreases rather strongly in the same period (Figs. 2b,e). The evolution of the precipitation rate shows large variability within the composites. The mean values being higher than the median reflects higher precipitation in a few events (Fig. 2c). 

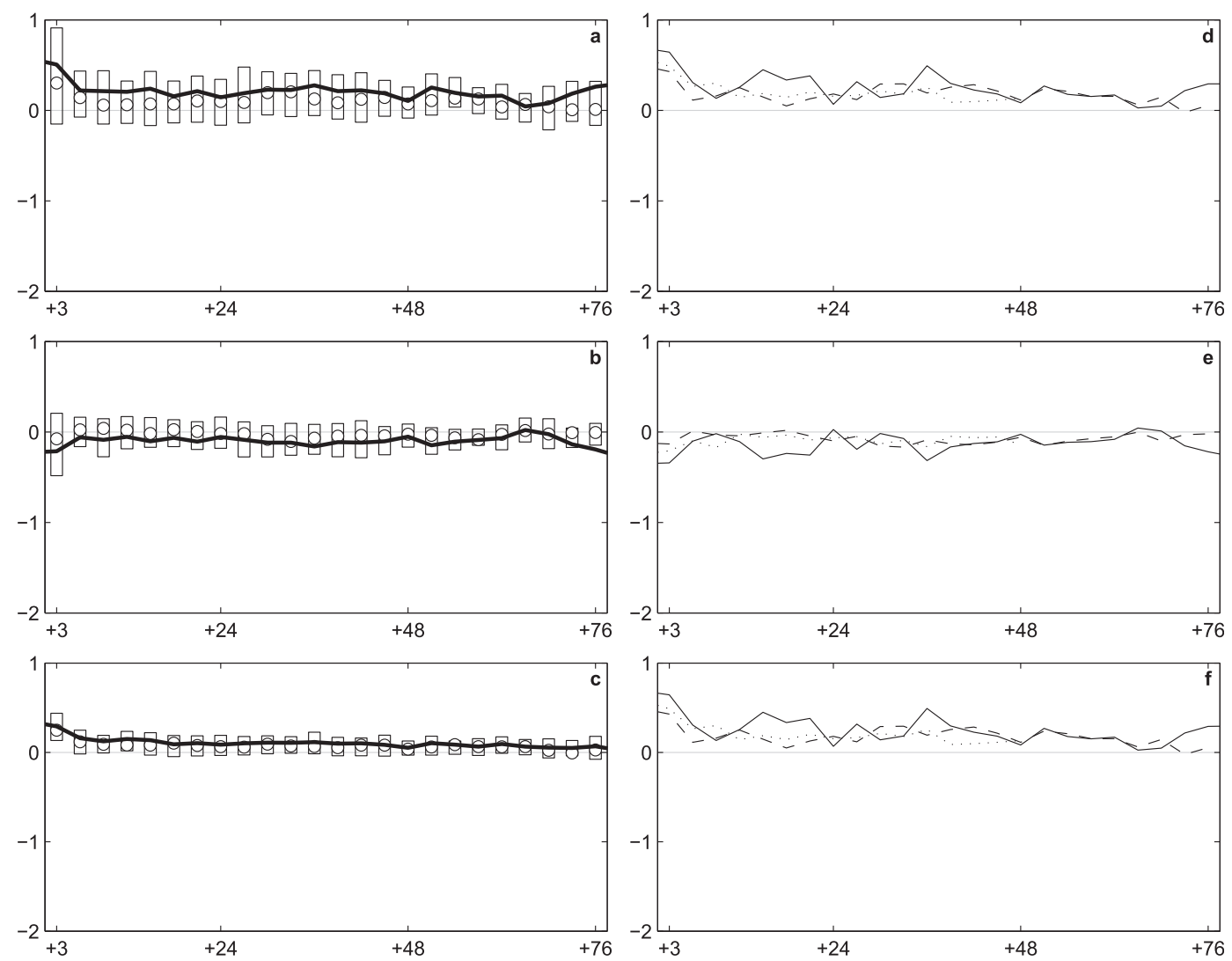

FIG. 6. As in Fig. 2, but for the (a),(d) direct; (b),(e) indirect; and (c),(f) total effect of the latent heating term on the 950-hPa GV tendencies $\left(10^{-9} \mathrm{~s}^{-2}\right)$.

\section{c. Evolution of reanalysis and $Z-O$ tendencies}

As we can see from Fig. 1, the storm advection tendencies are almost zero at the cyclone center (see Part I, section 4 for explanation). This means that the $\mathrm{Z}-\mathrm{O}$ tendencies at the cyclone center are the quasiLagrangian changes in the GV induced by the columnintegrated $\mathrm{Z}-\mathrm{O}$ forcing processes. Figures $3 \mathrm{a}$ and $3 \mathrm{~b}$ show the composite life cycle of reanalysis and Z-O tendencies at the cyclone center. Both tendencies are consistently negative in the entire decaying phase. Despite the large variability in both tendencies, there is high temporal correlation between the reanalysis and estimated $\mathrm{Z}-\mathrm{O}$ tendencies, and the maximum dissipation rate in both occurs at $+6 \mathrm{~h}$. The $\mathrm{Z}-\mathrm{O}$ tendencies are, however, weaker than the reanalysis tendencies for most of the period. The subcomposites DAY2, DAY3, and DAY4 (Figs. 3c,d) exhibit two additional features: first, the higher variability seen in the first $24 \mathrm{~h}$ is mainly due to different tendencies in the subcomposites; second, while all DAY2, DAY3, and DAY4 cyclones undergo a relatively strong decay in the earlier periods, the DAY3 and DAY4 cyclones consistently experience weaker decay at later times.

\section{Contributions of individual forcing terms}

\section{a. Evolution of vertically integrated quantities}

We have shown that the cyclone center $\mathrm{Z}-\mathrm{O}$ tendency is consistently negative throughout the decay. Here, we examine the vertically integrated $\mathrm{GV}$ tendencies at $950 \mathrm{hPa}$ induced by individual $\mathrm{Z}-\mathrm{O}$ forcing terms at the cyclone center. Figure 4 displays the evolution of 950-hPa $\mathrm{GV}$ tendencies attributed to the vorticity advection term. The direct effect (Figs. 4a,d) strongly reduces the 950-hPa CGV during the first $12 \mathrm{~h}$ of the decay. This negative contribution remains rather unchanged for the entire decay period in the DAY2 cyclones. For the DAY3 and DAY4 cyclones, the direct effect decreases remarkably after $24 \mathrm{~h}$ before increasing at the end of the decay period. It should be mentioned that the DAY3 and DAY4 cyclones may experience splitting, remerging, or merging with other cyclones during their long and slow decay. Wernli and Schwierz (2006) show that such evolutions are particularly tricky for the tracking of cyclones. Nevertheless, the weakening of the dissipation mechanism seen in the DAY3 and DAY4 subcomposites manifests the synoptic-scale conditions in which the cyclone exists, such 

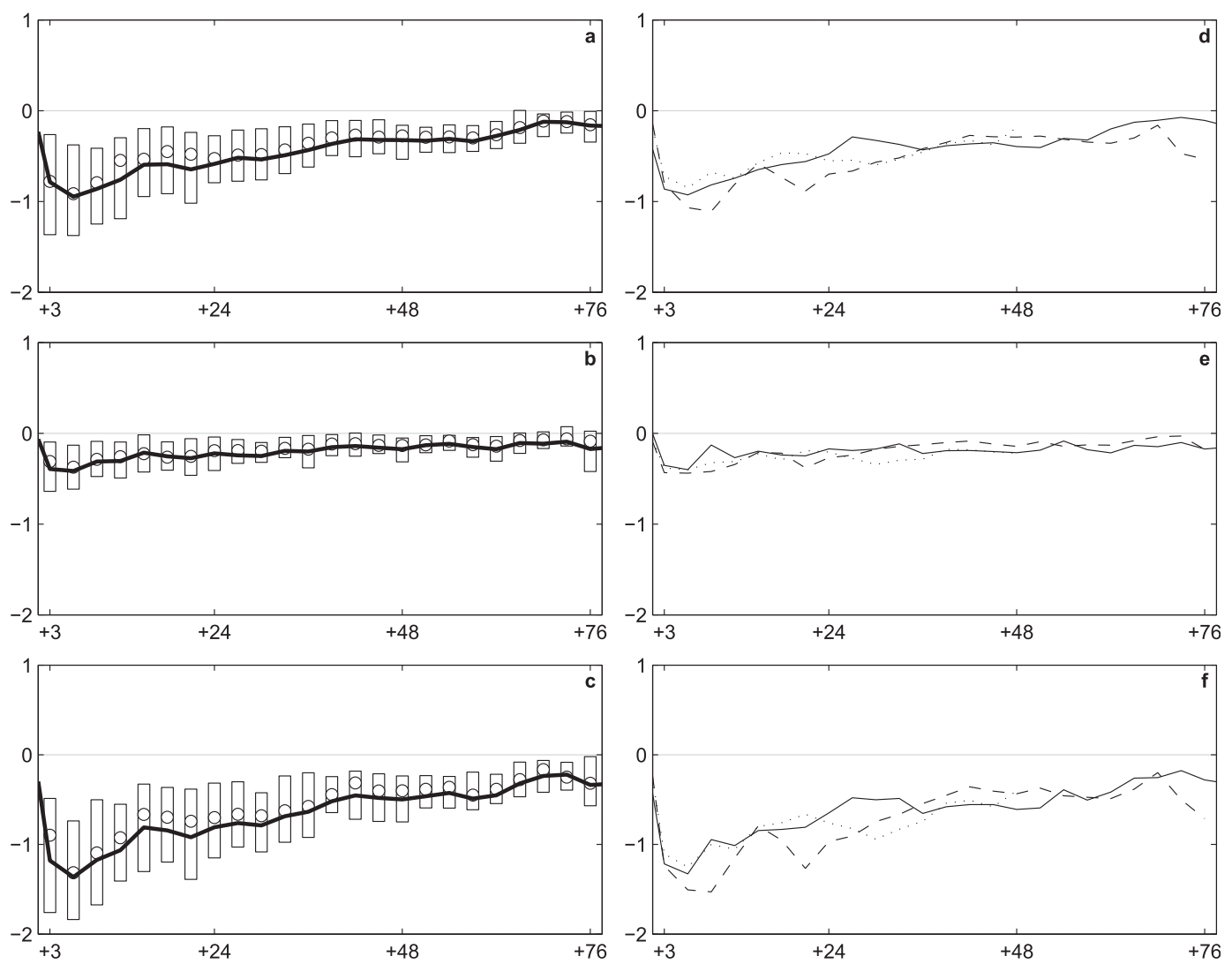

FIG. 7. As in Fig. 2, but for the $950-\mathrm{hPa} \mathrm{GV}$ tendencies $\left(10^{-9} \mathrm{~s}^{-2}\right)$ attributed to the (a),(d) direct; (b),(e) indirect; and (c),(f) total effect of the ageostrophic vorticity tendency term.

as the interaction of troughs aloft and the upper-level dynamics. The indirect effect (Figs. 4b,e) of vorticity advection is to generate $950-\mathrm{hPa} \mathrm{CGV}$, especially at the beginning of decay. This results in a weak negative-and for a few events a weak positive-total contribution (Figs. $4 \mathrm{c}, \mathrm{f})$. The end of the cyclone decay is dominated by the negative effect of anticyclonic vorticity advection.

Rather than being similar to the vorticity advection term, the total temperature advection term contribution (Fig. 5c) is, on average, much weaker. It is the positive indirect effect (Fig. 5b) that cancels substantially the negative direct effect (Fig. 5a), especially in the early part of the decay. The weak forcing by advection of air masses at the end of the decay period indicates the barotropic environment of dissipating cyclones. A common feature in all subcomposites is the negative direct effect in the first $12 \mathrm{~h}$ (Fig. 5d). This cyclolysis effect was reported in Rolfson and Smith (1996), Rausch and Smith (1996), Morris and Smith (2001), and Parsons and Smith (2004). For the DAY4 cyclones, however, temperature advection acts to moderate the dissipation by generating weak $950-\mathrm{hPa} \mathrm{CGV}$ midway during the decay (Figs. 5d,f).
The direct effect of latent heating is to generate 950-hPa CGV (Fig. 6a). This positive contribution is also seen in the total effect (Fig. 6c) and becomes nearly zero as the cyclone dissipates. Meanwhile, the indirect effect of adiabatic cooling and/or warming attributed to the latent heating is generally weak (Figs. 6b,e). The negative direct effect observed for the filling cyclones over land (e.g., Rolfson and Smith 1996; Morris and Smith 2001) is also seen in a number of selected marine ETCs, though it is not a dominant feature. Note that the differences between mean and median values in the direct effect, as well as the variability of tendencies, vanish in the total effect (Fig. 6c). There is a gradual decrease in the latent heating term contribution in all DAY2, DAY3, and DAY4 cyclones, but the contribution remains positive (Figs. 6d,f). The ageostrophic vorticity tendency term (Fig. 7) takes large negative values, especially at the first $12 \mathrm{~h}$ of the decay period. Parsons and Smith (2004) also show that the contribution from ageostrophic vorticity tendency term is important during the explosive development and decay of a marine storm over the North Atlantic. Interestingly, the total effect (Fig. 7c) is even larger because the indirect effect 

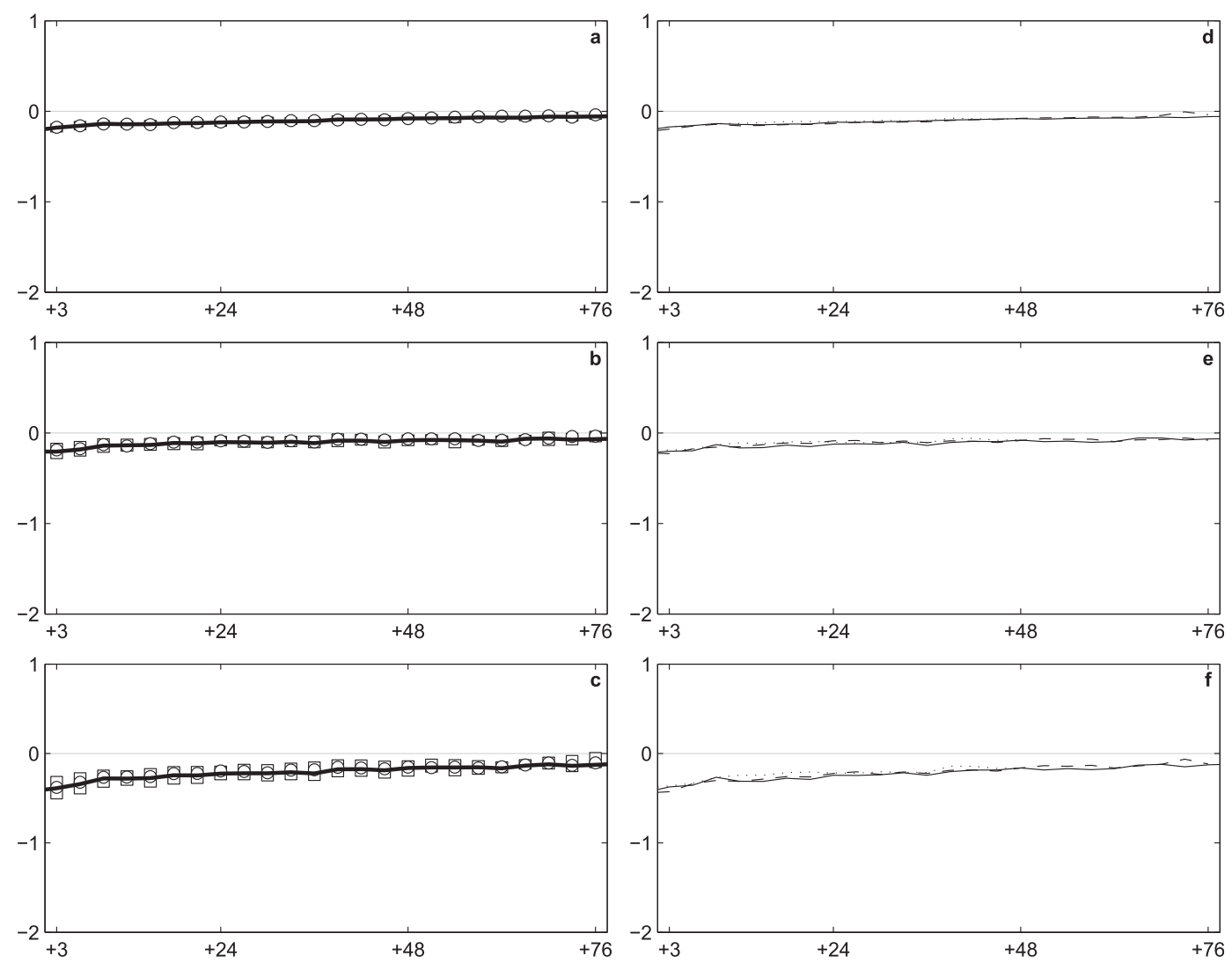

FIG. 8. As in Fig. 2, but for the (a),(d) direct; (b),(e) indirect; and (c),(f) total effect of the friction term on the 950-hPa $\mathrm{GV}$ tendencies $\left(10^{-9} \mathrm{~s}^{-2}\right)$.

(Fig. 7b) is also negative. The same sign of directly and indirectly induced GV tendencies is also seen for the contributions by the friction term (Fig. 8). The small variabilities in the total effect of the friction are associated with the indirect effect, which indicates the variability in the Ekman pumping strength (Holton and Hakim 2013): that is, secondary circulation and static stability in the boundary layer. Our composite results for the sensible heating term in the $\mathrm{Z}-\mathrm{O}$ equation (not shown here) suggest that the 950-hPa GV tendencies induced by the surface fluxes over ocean are very small.

\section{b. Evolution of contribution profiles}

To better understand the role of forcing processes at different pressure levels during the decay, we construct the vertical profiles of each forcing term over the cyclone center following Eqs. (17) and (18) in Rausch and Smith (1996). All quantities shown in the vertical time cross sections are the mean values. It should be mentioned that the profiles of median values (not shown) are, to a large extent, similar to the mean values. Figures $9 \mathrm{a}-\mathrm{c}$ show the contributions from each pressure level to the $950-\mathrm{hPa} \mathrm{GV}$ tendencies induced by the vorticity advection. The anticyclonic vorticity advections occur at almost all levels at the beginning of the decay (Fig. 9a). This prominent structure demonstrates that in the initial phase of the decay, the surface cyclone and the trough aloft are vertically stacked and, as the decay progresses, the upper trough moves slightly downstream from the surface low. In addition to the maximum quantities at upper levels, a secondary maximum is also present in the lower troposphere. Grotjahn (1996) and Räisänen (1997) show that this low-level forcing is induced by the divergent part of the wind. The positive indirect effect below $300 \mathrm{hPa}$ (Fig. $9 \mathrm{~b})$, particularly in the beginning of the decay, is mainly related to the Laplacian effect (horizontal pattern of induced vertical motions), which is of the same sign as adiabatic cooling (Figs. 10a,b). In turn, the negative indirect effects above $300 \mathrm{hPa}$ are related to the adiabatic cooling in the rising air. The total effect of the vorticity advection (Fig. 9c) is negative at upper and lower levels because of the anticyclonic vorticity advection and positive in midtropospheric levels because of the indirect effect of vertical motions. The negative effect is larger; hence, the vertically integrated contribution 

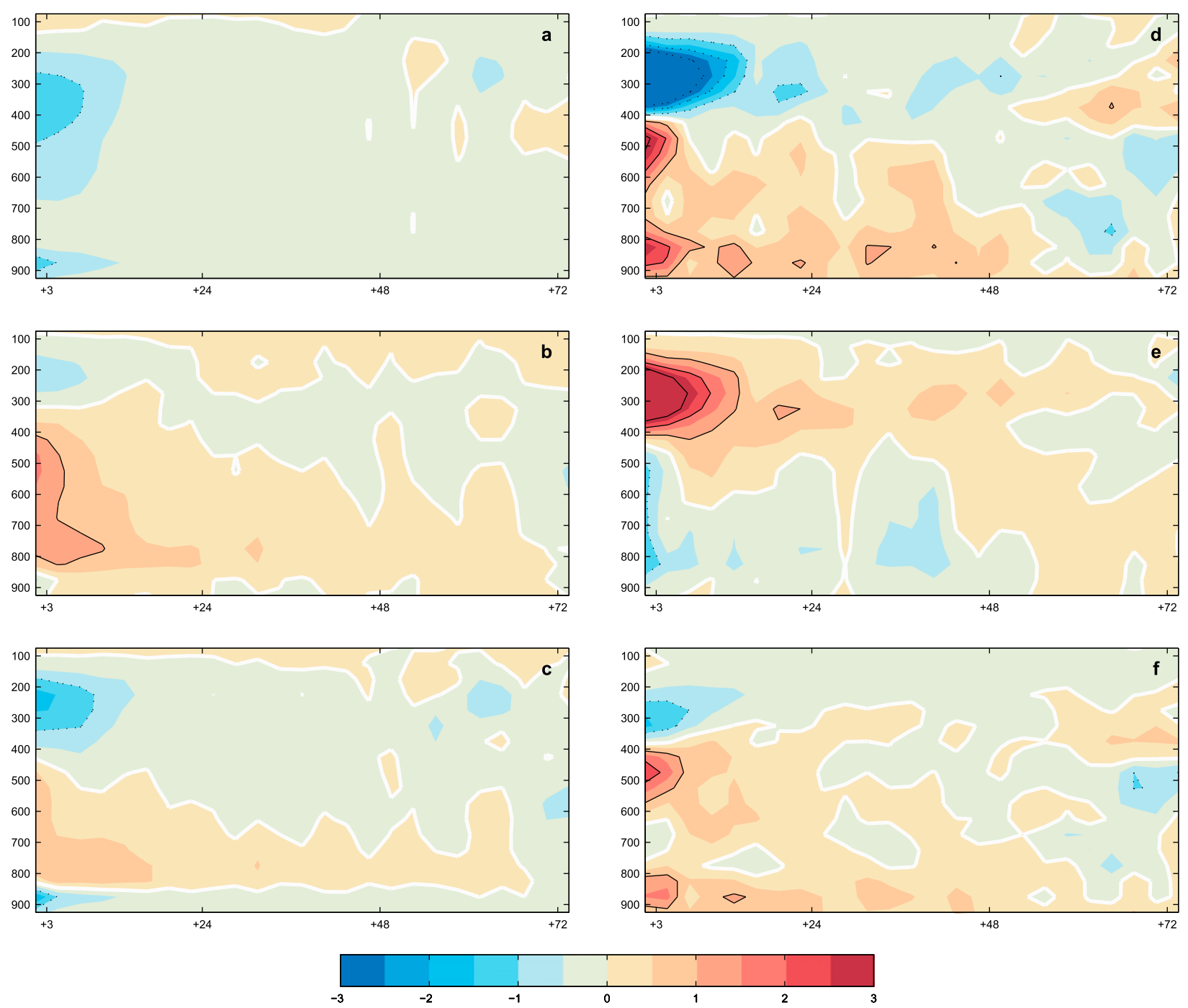

FIG. 9. Time-pressure cross-sectional profiles $\left(10^{-10} \mathrm{~s}^{-2}\right)$ of (a) direct, (b) indirect, and (c) total effects of the vorticity advection and (d) direct, (e) indirect, and (f) total effects of the temperature advection. The vertical axis is pressure (hPa), and the horizontal is time (h) after $t_{c}$. The white line shows the zero values.

by the vorticity advection term is to decrease the 950-hPa CGV.

The direct effect of the temperature advection is to reduce the CGV mainly via the upper cold-air advection (Fig. 9d). Meanwhile, there are positive contributions at the lower levels despite the fact that cold-air advection is present in the entire depth of the troposphere (Figs. $10 \mathrm{c}, \mathrm{d})$. The ability of cold-air advection to cause divergence means that the cyclone centers are usually located in the outer reaches of the advection regions. The low-level cold-air advection was shown to play a significant role in cyclolysis for land cyclones (Morris and Smith 2001; Rolfson and Smith 1996). The direct effects shown in Fig. 9d are similar to the results of Rausch and Smith (1996), in the respect that the low-level cold-air advection over the cyclone center may generate $950-\mathrm{hPa}$ CGV and that it is only a distant secondary contributor to the decay. The indirect effect of the temperature advection (Fig. 9e) is of opposite sign and weaker in magnitude, resulting in a weak total effect (Fig. 9f). The evolution of the vertical profiles of the total effect for the vorticity advection and temperature advection (Figs. $9 \mathrm{c}, \mathrm{f})$ suggests that the layer of maximum forced convergence moves toward lower levels as the cyclone dissipates. This is indicative of the upper-level trough vanishing and the depth of the cyclonic circulation reducing over the cyclone center.

Figures 11a-c show profiles of latent heat release. Comparing these figures with Fig. 13 in Part I for the development phase, it can be noted that the effect of 

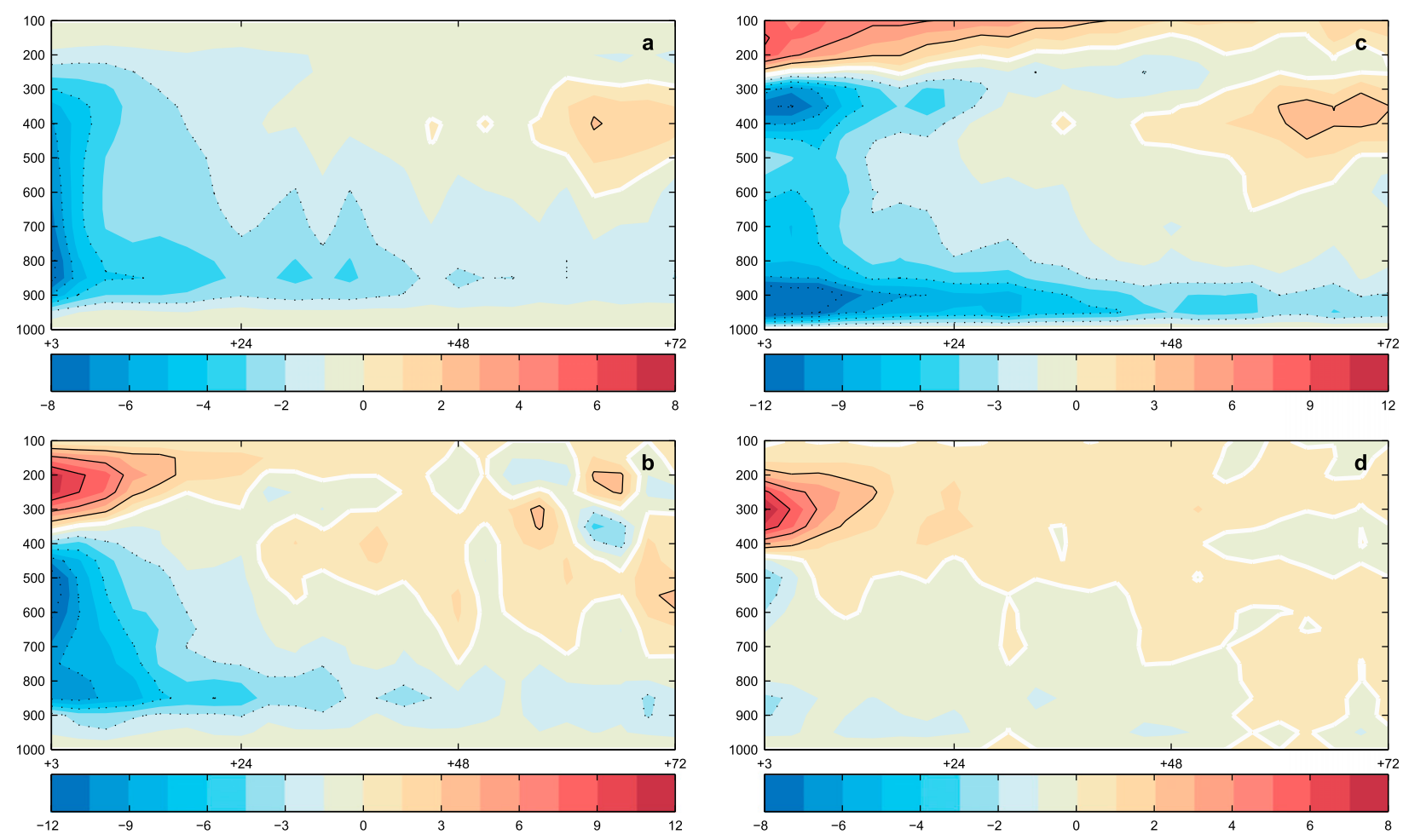

FIG. 10. Time-pressure cross section of (a) the vertical motion induced by the horizontal vorticity advection $\left(10^{-4} \mathrm{~Pa} \mathrm{~s}^{-1}\right)$ and $(\mathrm{b})$ its Laplacian $\left(10^{-16} \mathrm{~s}^{-1} \mathrm{~m}^{-2}\right)$ and (c) the horizontal temperature advection $\left(10^{-5} \mathrm{~s}^{-2}\right)$ and (d) its Laplacian $\left(10^{-15} \mathrm{~s}^{-2}\right)$ for the same period in Fig. 7. The white line shows the zero values.

latent heat release is dramatically reduced in the decaying phase. The positive direct effects seen in the lower levels (Fig. 11a) are associated with the release of latent heat over the cyclone center (not shown). This persistent maximum layer is located at $800-700 \mathrm{hPa}$ and is also present in the total effect (Fig. 11c). It is evident from Fig. 11b that the effect of induced vertical motion by the shallow condensational heating is minimal. Positive ageostrophic vorticity tendencies at the beginning of the decay are prevalent at pressure levels below $200 \mathrm{hPa}$ (Fig. 11d). The indirect effect of the ageostrophic vorticity tendency (Fig. 11e) is also negative in the upper and lower levels. This leads to relatively large negative tendencies in the total effect (Fig. 11f). The strongest total opposing effect of friction is observed at the $850 \mathrm{hPa}$ during the first $18 \mathrm{~h}$ of the decay (not shown).

Figure 12 represents the vertical profile made by summing all the $\mathrm{Z}-\mathrm{O}$ forcing terms. The summed direct effects (Fig. 12a) reflect the importance of the upperlevel dynamics, particularly at the beginning of decay. The secondary contribution to the decay seen below $850 \mathrm{hPa}$ in the boundary layer is attributed to the anticyclonic vorticity advection, friction, and positive ageostrophic vorticity tendency. The summed indirect effects (Fig. 12b) show that the upper-air (above $300 \mathrm{hPa}$ ) adiabatic warming mainly forced by the coldair advection opposes the cyclolysis, whereas the lowlevel (below $700 \mathrm{hPa}$ ) adiabatic cooling due to fairly strong vertical motions generates negative GV tendencies. The summed total effects (Fig. 12c) act to dissipate the 950-hPa CGV via convergence induced at low and upper levels and to generate weak 950-hPa CGV at midtropospheric levels.

\section{c. Contributions for the entire decaying stage}

The bar graphs in Fig. 13 summarize the direct, indirect, and total effects of the $\mathrm{Z}-\mathrm{O}$ forcing terms for the entire decaying phase. All quantities are the composite mean contributions at the cyclone center defined as the average of the contributions by the individual forcing terms at the cyclone center for the cyclones of interest during the entire period of decay. We use the 25th-75th percentiles to show the variability within the composite cyclones. Table 1 displays the corresponding percentages of the averaged mean contributions. We see that the direct effect of vorticity advection, temperature advection, ageostrophic vorticity tendency, and friction is to reduce the $\mathrm{CGV}$ for almost all cyclone events, while the release of latent heat increases the CGV slightly and 

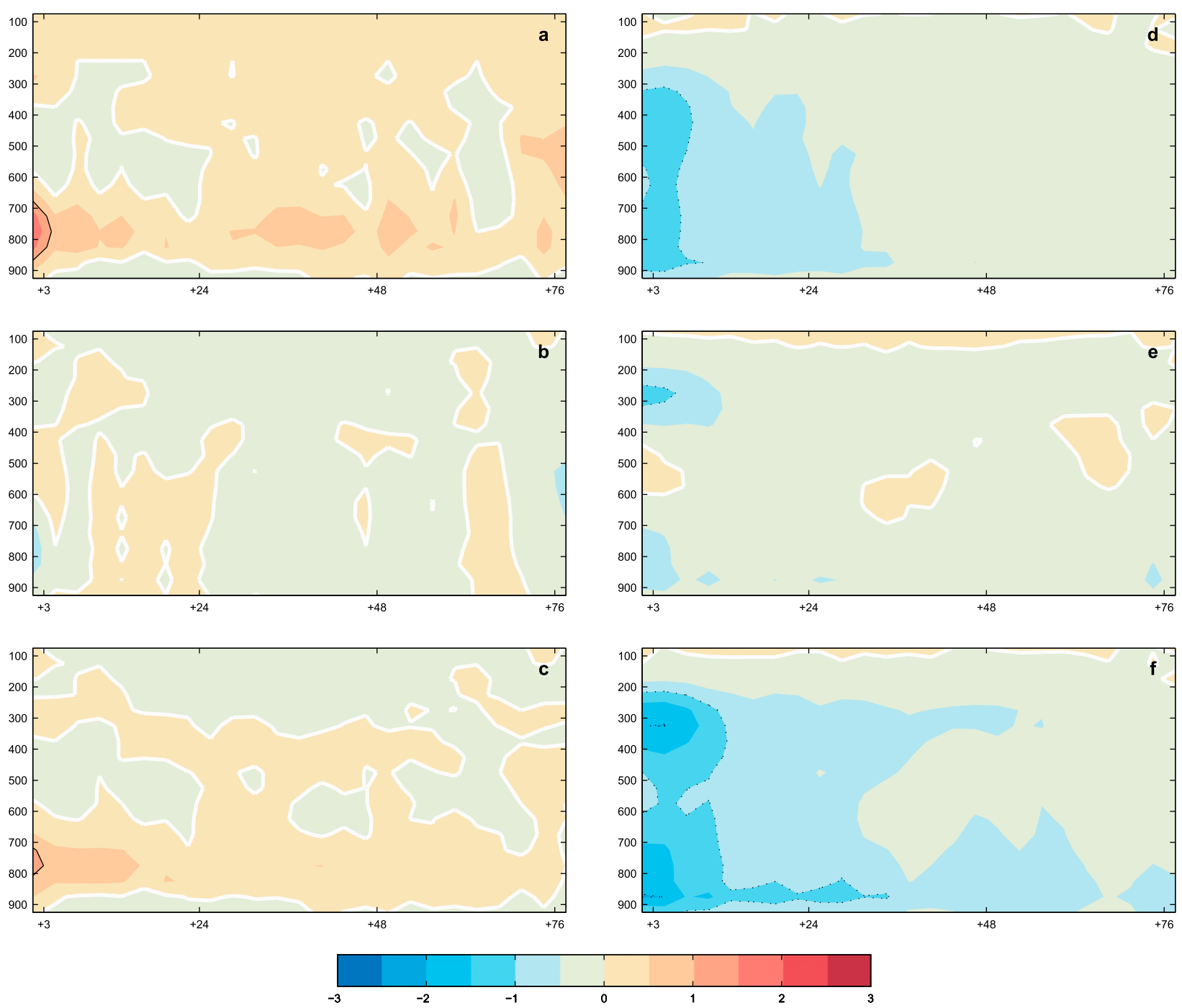

FIG. 11. As in Fig. 7, but for the (a) direct, (b) indirect, and (c) total effect of the latent heating and (d) direct, (e) indirect, and (f) total effect of the ageostrophic vorticity tendency.

the effect of sensible heating is negligible. The surprising small negative direct effect of the temperature advection term is because of the positive effects in the DAY4 cyclones (see Fig. 5d). The indirect effects of ageostrophic vorticity tendency, vorticity advection, and temperature advection are apparently more case dependent (Fig. 13b). Contrasting the direct (Fig. 13a) and total effects (Fig. 13c), we find that the range of variability in the total effects is smaller, except for the ageostrophic vorticity tendency term. Moreover, the indirect effects of the vorticity advection, temperature advection, and latent heating terms counteract the direct effects, while for the ageostrophic vorticity tendency and friction terms, they reinforce the direct effects. The sign of the total effects is, however, similar to that in the direct effects in all $\mathrm{Z}-\mathrm{O}$ terms. The interesting and remarkable feature seen in the total effects is the large magnitude and variability of tendencies attributed to the ageostrophic vorticity tendency term.

\section{Concluding remarks}

This study is an effort to further explore the weakening and termination phase of winter North Atlantic midlatitude low pressure systems by means of a paired form of the $\mathrm{Z}-\mathrm{O}$ and omega equations using the Modern-Era Retrospective Analysis for Research and Applications (MERRA). The composite diagnosis method presented in Part I of this work for the development phase of 100 intense, long-lived winter events (1979-2009) was applied for the period of decay in the present paper. The main objective for using the partitioned 

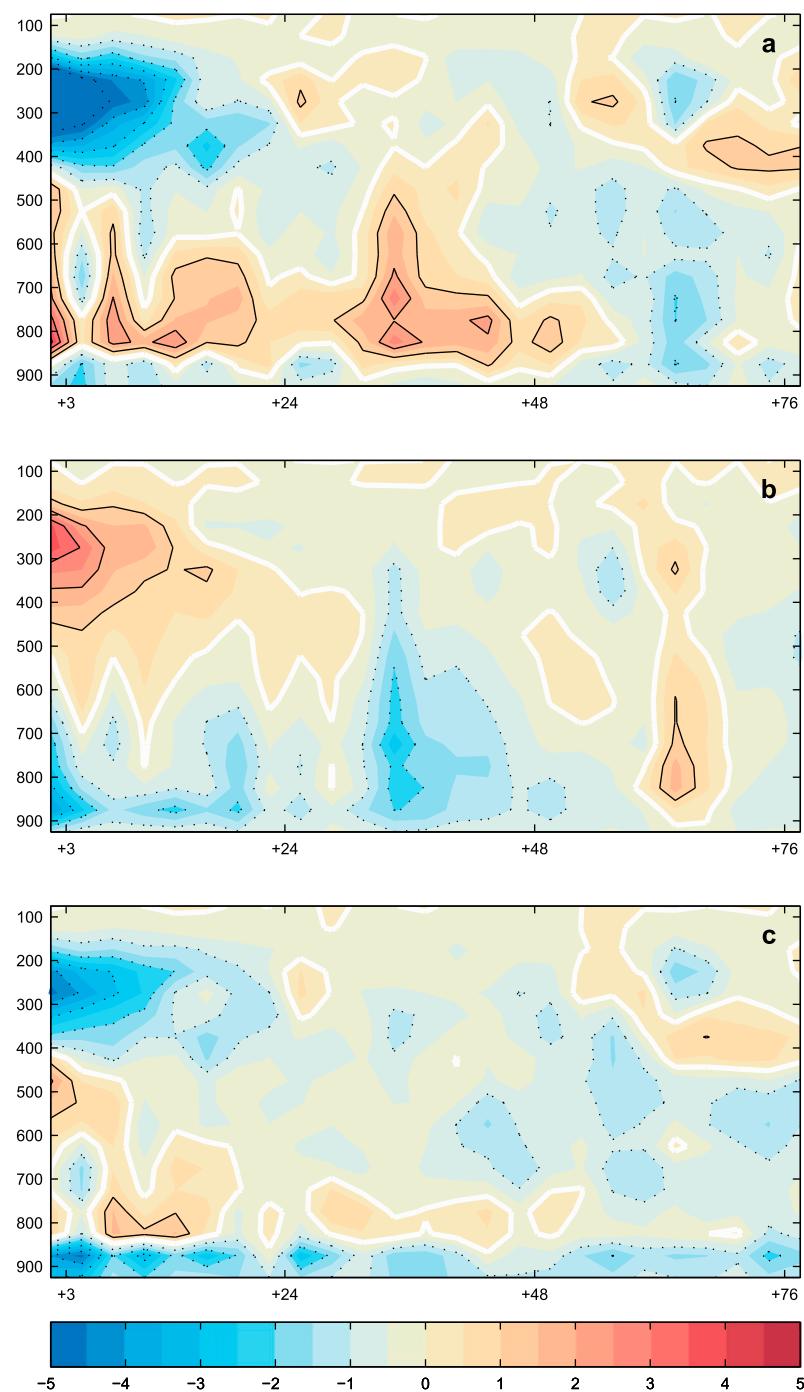

FIG. 12. As in Fig. 7, but for the summed (a) direct, (b) indirect, and (c) total effects of all $\mathrm{Z}-\mathrm{O}$ forcing terms.

$\mathrm{Z}-\mathrm{O}$ tendency equation was to investigate the total effects (i.e., the direct effect of dynamical and thermal mechanisms and the indirect effect of the adiabatic cooling term) of forcing processes that dissipate the near-surface $\mathrm{CGV}$ at the cyclone center.

The main conclusions from our analysis at the cyclone center are as follows:

- The total effects of vorticity advection and temperature advection terms are modest, while ageostrophic vorticity tendency and friction terms play a greater role in dissipating the $950-\mathrm{hPa} \mathrm{CGV}$.

- The influence of the friction on the dissipation of 950-hPa CGV is considerable because the adiabatic cooling associated with the Ekman pumping in the boundary layer reinforces the damping effect of the friction.
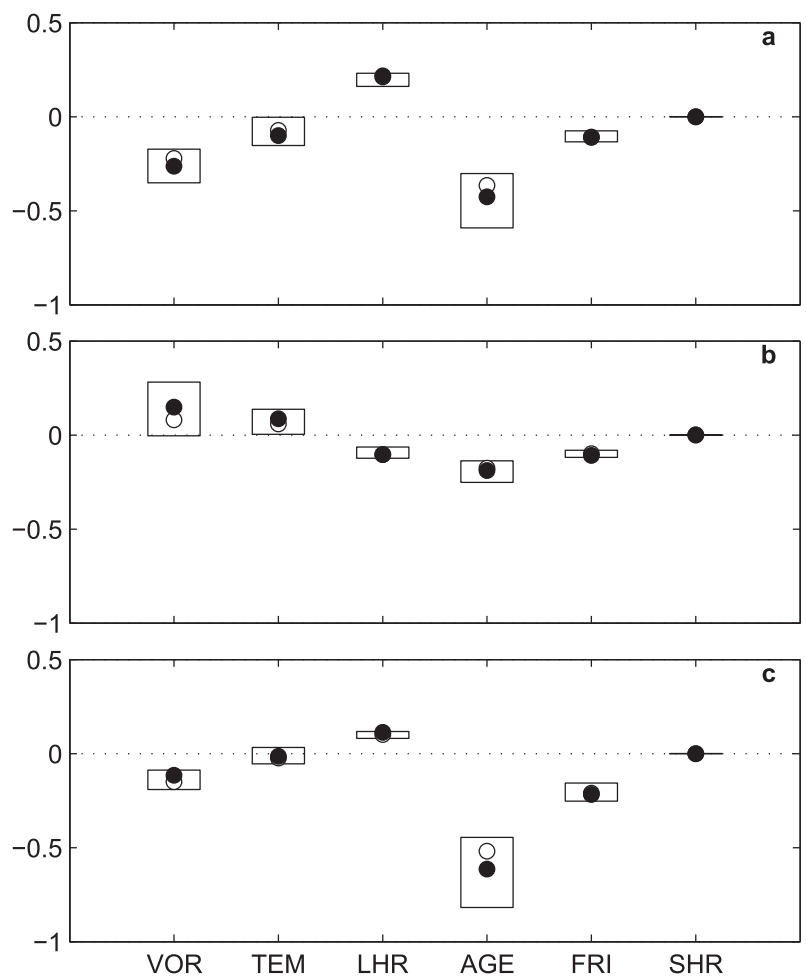

FIG. 13. (a) Direct, (b) indirect, and (c) total mean contributions $\left(10^{-9} \mathrm{~s}^{-2}\right)$ to the $950-\mathrm{hPa} \mathrm{GV}$ tendency at the cyclone center for the entire decaying phase attributed to the vorticity advection (VOR), temperature advection (TEM), latent heat release (LHR), ageostrophic vorticity tendency (AGE), friction (FRI), and sensible heating (SHR) terms. Boxes are the 25th-75th percentile, and white and black-filled circles show median and mean values, respectively.

- The commencement of the decay is associated with anticyclonic vorticity advection and cold-air advection aloft that force convergence and damping of the evacuation of the air from the lower levels. Thus, the winter cyclone decay over the North Atlantic occurs mainly because of the near-zero or negative tilt of the upper-level trough and the surface cyclone.

- The low-level cold-air advection plays a secondary role in the decay, apparently because the Laplacian operator in the $\mathrm{Z}-\mathrm{O}$ equation dictates a sensitivity to horizontal distribution, which is vigorous when the forcing field is relatively weak and/or its maximum is farther removed from the cyclone center.

- The variability seen especially in the contributions by the temperature advection and latent heating terms (Figs. 5 and 6) highlights the large differences in the dynamics of the weakening cyclones.

- We see that the dynamics is different at the beginning of the decay than in the later stages; the upper-air processes play an essential role in triggering decay, but the lower-air processes take a greater part in termination of the cyclonic circulation. 
TABLE 1. Percentage of averaged direct, indirect, and total mean contributions to the $950-\mathrm{hPa}$ GV tendency at the cyclone center for the entire decaying phase attributed to the vorticity advection (VA), temperature advection (TA), latent heating (LH), ageostrophic vorticity tendency (AG), friction (FR), and sensible heating $(\mathrm{SH})$ terms. The larger values are boldface. Negative (positive) signs correspond to the dissipation (production) of 950-hPa GV.

\begin{tabular}{lcccccc}
\hline \hline & VA & TA & LH & AG & FR & SH \\
\hline Direct & $-\mathbf{2 7} \%$ & $-11 \%$ & $+17 \%$ & $-\mathbf{3 5} \%$ & $-10 \%$ & $-0.01 \%$ \\
Indirect & $+16 \%$ & $+14 \%$ & $-19 \%$ & $-\mathbf{3 0} \%$ & $-21 \%$ & $+0.001 \%$ \\
Total & $-18 \%$ & $-4 \%$ & $+8 \%$ & $-\mathbf{4 4} \%$ & $-\mathbf{2 6} \%$ & $-0.20 \%$ \\
\hline
\end{tabular}

Though the surprisingly large total contributions by the ageostrophic vorticity tendency term could include some computationally induced overestimations, the supporting direct and indirect effects show that the role of this term in the $\mathrm{Z}-\mathrm{O}$ equation is significant during the decay. It would be interesting to apply the partitioning technique for the ageostrophic vorticity tendency term used by Lupo (2002) in order to reduce the time-differencing errors and to analyze its effect in modulating the remaining forcing terms. Because vertical motions act as a forcing for changes in the ageostrophic wind, the partitioning would distribute a portion of the $950-\mathrm{hPa} \mathrm{GV}$ tendencies to the indirect effects of the remaining forcing terms.

Rapid cyclolysis (large negative GV tendencies) is expected to influence the mean composite contributions. Therefore, our results for the beginning of the decaying phase are in agreement with the findings of Martin and Marsili (2002). They show that the rapid surface cyclolysis is largely the result of the upper-level potential vorticity (PV) anomaly, thus emphasizing the largescale dynamics aloft as the primary forcing for the negative surface height tendencies. In our composite result, the lower-tropospheric forcing processes play a secondary role in dissipating the $950-\mathrm{hPa} \mathrm{CGV}$ at the cyclone center. However, the low-level damping effect is possibly stronger than what we have estimated here because of the bias in the total Z-O tendencies. We have shown that calculated $\mathrm{Z}-\mathrm{O} \mathrm{GV}$ tendencies consistently anticipated the negative sign of the reanalysis GV tendencies, but the Z-O tendencies were weaker $(\sim 30 \%-40 \%)$. To find the possible source for the underestimation, we recalculated the $\mathrm{Z}-\mathrm{O}$ tendencies by using the MERRA vertical motion field. Surprisingly, the underestimation of tendencies reduced to less than $10 \%-20 \%$. The failure of the omega equation to produce weak low-level adiabatic cooling during the decay is therefore asserted to be one of the main reasons for the weaker $\mathrm{Z}-\mathrm{O}$ tendency values. In future work, we will attempt to improve estimation of low-level vertical motions and associated adiabatic cooling in the context of the cyclone decay.
Acknowledgments. This work was financed by the Norwegian Research Council SFF Grant to the Bjerknes Centre for Climate Research and the Norwegian Research Council project EarthClim. We thank Professor Joe La Casce, Professor Gudrun Magnusdottir, and Dr. Camille $\mathrm{Li}$ for their suggestions regarding the presentation of results and displaying of figures. The authors are likewise grateful to Professor Emeritus Phillip Smith for his insight and comments on the manuscript and Dr. Kevin Hodges for providing the cyclone trajectories. MERRA data used in this study have been provided by the Global Modeling and Assimilation Office (GMAO) at NASA Goddard Space Flight Center through the NASA GES DISC online archive.

\section{REFERENCES}

Azad, R., and A. Sorteberg, 2014: The vorticity budgets of North Atlantic winter extratropical cyclones life cycle in MERRA reanalysis. Part I: Development phase. J. Atmos. Sci., 71, 3109-3128, doi:10.1175/JAS-D-13-0267.1.

Bengtsson, L., K. I. Hodges, and N. Keenlyside, 2009: Will extratropical storms intensify in a warmer climate? J. Climate, 22, 2276-2301, doi:10.1175/2008JCLI2678.1.

Bjerknes, J., and H. Solberg, 1922: Life cycle of cyclones and the polar front theory of atmospheric circulation. Geofys. Publ., 3, 3-18.

Carlson, T. N., 1994: Mid-Latitude Weather Systems. Harper Collins Academic, 507 pp.

Doyle, J. D., 1995: Coupled ocean wave/atmosphere mesoscale model simulations of cyclogenesis. Tellus, 47A, 766-778, doi:10.1034/j.1600-0870.1995.00119.x.

Grotjahn, R., 1996: Vorticity equation terms for extratropical cyclones. Mon. Wea. Rev., 124, 2843-2858, doi:10.1175/ 1520-0493(1996)124<2843:VETFEC >2.0.CO;2.

Holton, J. R., and G. J. Hakim, 2013: An Introduction to Dynamic Meteorology. 5th ed. International Geophysics Series, Vol. 88, Academic Press, 552 pp.

Lupo, A. R., 2002: Ageostrophic forcing in a height tendency equation. Mon. Wea. Rev., 130, 115-126, doi:10.1175/ 1520-0493(2002)130<0115:AFIAHT > 2.0.CO;2.

_ P. J. Smith, and P. Zwack, 1992: A diagnosis of the explosive development of two extratropical cyclones. Mon. Wea. Rev., 120, 1490-1523, doi:10.1175/1520-0493(1992)120<1490: ADOTED $>2.0 . \mathrm{CO} ; 2$.

Martin, J. E., and N. Marsili, 2002: Surface cyclolysis in the North Pacific Ocean. Part II: Piecewise potential vorticity diagnosis of a rapid cyclolysis event. Mon. Wea. Rev., 130, 1264-1281, doi:10.1175/1520-0493(2002)130<1264:SCITNP>2.0.CO;2.

_ R. D. Grauman, and N. Marsili, 2001: Surface cyclolysis in the North Pacific Ocean. Part I: A synoptic climatology. Mon. Wea. Rev., 129, 748-765, doi:10.1175/1520-0493(2001)129<0748: SCITNP $>2.0 . C O ; 2$.

Morris, W. E., and P. J. Smith, 2001: Cyclolysis: A diagnosis of two extratropical cyclones. Mon. Wea. Rev., 129, 2714-2729, doi:10.1175/1520-0493(2001)129<2714:CADOTE > 2.0.CO;2.

Parsons, K. E., and P. J. Smith, 2004: An investigation of extratropical cyclone development using a scale-separation technique. Mon. Wea. Rev., 132, 956-974, doi:10.1175/1520-0493(2004)132<0956: AIOECD $>2.0 . C O ; 2$. 
Räisänen, J., 1997: Height tendency diagnostics using a generalized omega equation, the vorticity equation, and a nonlinear balance equation. Mon. Wea. Rev., 125, 1577-1597, doi:10.1175/ 1520-0493(1997)125<1577:HTDUAG>2.0.CO;2.

Rausch, R. L. M., and P. J. Smith, 1996: A diagnosis of a modelsimulated explosively developing extratropical cyclone. Mon Wea. Rev., 124, 875-904, doi:10.1175/1520-0493(1996)124<0875: ADOAMS $>2.0 . C O ; 2$.

Rolfson, D. M., and P. J. Smith, 1996: A composite diagnosis of synoptic-scale extratropical cyclone development over the United States. Mon. Wea. Rev., 124, 1084-1099, doi:10.1175/ 1520-0493(1996)124<1084:ACDOSS >2.0.CO;2.

Schultz, D. M., and G. Vaughan, 2011: Occluded fronts and the occlusion process: A fresh look at conventional wisdom Bull. Amer. Meteor. Soc., 92, 443-466, doi:10.1175/ 2010BAMS3057.1.
Shapiro, M. A., and D. Keyser, 1990: Fronts, jet streams and the tropopause. Extratropical Cyclones: The Erik Palmén Memorial Volume, C. W. Newton and E. O. Holopainen, Eds., Amer. Meteor. Soc., 167-191.

Walthorn, K. D., and P. J. Smith, 1998: The dynamics of an explosively developing cyclone simulated by a general circulation model. Mon. Wea. Rev., 126, 2764-2781, doi:10.1175/ 1520-0493(1998)126<2764:TDOAED > 2.0.CO;2.

Wernli, H., and C. Schwierz, 2006: Surface cyclones in the ERA-40 dataset (1958-2001). Part I: Novel identification method and global climatology. J. Atmos. Sci., 63, 2486-2507, doi:10.1175/ JAS3766.1.

Zwack, P., and B. Okossi, 1986: A new method for solving the quasi-geostrophic omega equation by incorporating surface pressure tendency data. Mon. Wea. Rev., 114, 655-666, doi:10.1175/1520-0493(1986)114<0655:ANMFST>2.0.CO;2. 